\title{
Evaluation of serum levels of copper and nutritional factors in patients with perthes disease
}

\begin{abstract}
Background: About a hundred years after the first reports about the disease Legg-CalvéPerthes that Perthes also called, since it is still the main cause of this disease is unknown.

Methods: In this RCT study blood level of zinc and copper in patient with perthes and control group with minor musculoskeletal trauma who were matched for age and sex were measured and compared.

Results: This study showed that low level of zinc and copper with Perthes patients compared with controls group with minor trauma referring to Imam Khomeini hospital of Ahvaz.

Conclusion: In this study lower level of zinc and copper in patient with perthes compared to control was demonstrated but zinc deficiency and copper to investigate the etiologic relationship with perthes disease requires further investigation. That the proof of this can be modified nutritional pattern of children with perthes disease be prevented.
\end{abstract}

Volume 6 Issue 7 - 2016

\author{
Mohammd Fakoor,' Payam Mohammad \\ Hoseini, ${ }^{2}$ Seyed Shahnam Moosavi, ${ }^{2}$ Amir \\ Aghaee Aghdam, ${ }^{3}$ Naser Sarrafan, ' Seyed \\ Abdolhossein Mehdinasab' \\ 'Professor of Orthopedic Surgery, Department of orthopedic, \\ Ahvaz Jundishapur University of medical science, Iran \\ ${ }^{2}$ Assistant professor of orthopedic surgery, Department of \\ orthopedic, Ahvaz Jundishapur University of medical science \\ ${ }^{3}$ Orthopaedic surgeon, Department of orthopedic, Ahvaz \\ Jundishapur University of medical science, Iran
}

\author{
Correspondence: Mohammad Fakoor, Professor of \\ Orthopedic Surgery, Department of orthopedic Hospital, Ahvaz \\ Jundishapur University of medical science, Iran \\ Emaildr_m_fakoor@yhoo.com
}

Received: April 26, 2016 | Published: December 30, 2016

\section{Background}

About a hundred years after the first reports about the disease Legg-Calvé-Perthes that Perthes also called, since it is still the main cause of this disease is unknown. Perthes with the loss of femoral head blood flow in growing children, between the ages of 2-13 years is determined and is considered as a vascular disease. The outbreak, one in every 1,200 children younger than 15 years is. 5-4 times more common in boys than girls. Limping, limb length discrepancy, pain and stiffness in the thigh and hip, leg pain and knee although the disorder often affects the hip joint. Common symptoms of the disease are usually gradual onset. Delay in treatment may cause permanent damage to bone and hip that joint replacement surgery is needed.

Children with developmental anomalies are at risk. ${ }^{1}$ Patients with moderate short stature, skeletal disproportionity, delayed skeletal maturity. ${ }^{2,3}$ Hall et al. have registered disharmony and disproportion in the growth of chicks suffered from a shortage of heavy metals. ${ }^{4}$ and low serum concentrations of manganese have been but this has not been confirmed. ${ }^{5}$ gluck et al. reported antithrombin deficiency in patients. ${ }^{6}$ Gluck et al. Also reported low fibrinolysis in patients who have smoking parents. ${ }^{7}$ There is association between disease and breech birth, low birth weight and parents older than average age. ${ }^{8}$ Is a multifactorial inheritance pattern has been proposed. ${ }^{9} \mathrm{~A}$ Nevelas and Burch have been reported..$^{10}$ This concept represents less common genetic cause in South Africa by Perthes in blacks compared with whites has been. ${ }^{11}$ The results of experimental studies in animals fed with food containing copper and zinc inadequate and also in human have shown that in some range of copper concentration many of symptoms associated with vascular disease.

\section{Method}

In this study blood level of zinc and copper in patient with perthes and control group with minor musculoskeletal trauma who were matched for age and sex were measured. Blood sample were taken through the needle of stainless steel with plastic pistons.3CC minimum volume blood samples to measure the serum was separated from the serum of patients and controls each was diluted with deionized water at a ratio of one to five flame atomic absorption spectrometry (air-acetylene mixture) spread their absorption at a wavelength of 213.8 Nano meters measured concentration of the samples by comparing peak with the peak of the standards used within (lit / mg100, 200, 300 and 400) were determined consumption standards of diluting the volume of appropriate standards save by glycerol diluted (50cc glycerol with deionized water to the volume 100 cc they were) were prepared serum levels of copper in the case and control groups after dilution directly serum samples in flame atomic absorption spectrometry (mixture of air and acetylene) scattered and absorbed water "in the wavelength of 324.8 nanometer . size copper concentrations of samples by comparing peak with standard peak usage ( 0.04 to $5 \mathrm{mmol}$ per liter) were determined Prostheses study on 22 patients referred to the orthopedic ward of Imam Khomeini hospital and minor trauma patients admitted hospital Imam Khomeini as the control group in terms of age and sex matched were also statistical software used SPSS software version 22 is by analyzing statistical test (t) test and Fisher's exact test and chi-square test Mantel square Huntley was statistically significant level was defined with $\mathrm{p}<0.05$.

\section{Results}

In our review of 22 cases and 24 control patients formed the study group of 22 patients, 21 patients (95.5) were male and 1 patient (4.5) were female. In the control group of 24 patients 21 ( 87.5 ) male and 3 patients (12.5) were women. A male patient was excluded due to the clotting test sample. Average copper level in the case group $0.737(\mathrm{PPM})$ with a standard deviation of 0.40 And the average copper level in the control group1.47 (PPM) with a standard deviation of the0.72.(table1) mean serum copper levels in patients with Perthes is lower than the average copper concentration in the control group. The average blood zinc concentration in patients with Perthes0.95 PPM with standard deviation of the 1.2 and mean blood zinc concentration 
in control group was 1.91 with standard deviation of 0.46 . (Table1) mean serum zinc levels in patients with Perthes is lower than the average zinc concentration in the control group. This study showed that low level of zinc and copper with Perthes patients compared with controls group with minor trauma referring to Imam Khomeini hospital of Ahvaz.

Table I Comparison between blood levels of copper and zinc with Perthes and controls.

\begin{tabular}{llll}
\hline $\mathbf{P}$ & $\begin{array}{l}\text { Group } \\
\text { The Control } \\
\text { Group }(\mathbf{n}=\mathbf{2 4})\end{array}$ & $\begin{array}{l}\text { Patient Group } \\
\mathbf{= 2} \mathbf{I})\end{array}$ & $\begin{array}{l}\text { Blood Levels of Copper } \\
\text { and Zinc }\end{array}$ \\
\hline $0 / 01$ & $1 / 47 \pm 0 / 72$ & $0 / 737 \pm 0 / 4$ & Blood levels of copper (ppm) \\
$0 / 03$ & $1 / 91 \pm 0 / 46$ & $0 / 95 \pm 1 / 2$ & Blood levels of zinc (ppm) \\
\hline
\end{tabular}

Nutritional factors on grain consumption between the two groups had no difference. But the consumption of fruit and fish and nuts was significantly lower in the patient group than the control group (Tables $2 \& 3)$.

Table 2 Comparison of nutritional factors between the two groups

\begin{tabular}{llll}
\hline $\mathbf{P}$ & $\begin{array}{l}\text { Group } \\
\text { Patient Group } \\
(\mathbf{n}=\mathbf{2} \text { I) }\end{array}$ & $\begin{array}{l}\text { The Control Group } \\
(\mathbf{n}=\mathbf{2 4})\end{array}$ & Nutritional Factors \\
\hline $0 / 0 / 09$ & $4 / 13 \pm 0 / 07$ & $3 / 86 \pm 0 / 07$ & Grains (per day) \\
$0 / 03$ & $0 / 71 \pm 0 / 05$ & $0 / 85 \pm 0 / 03$ & Fruits (per day) \\
$0 / 0 / 85$ & $10 / 8 \pm 0 / 11$ & $0 / 98 \pm 0 / 09$ & Vegetables (per day) \\
$0 / 02$ & $0 / 21 \pm 0 / 02$ & $0 / 34 \pm 0 / 02$ & Fish (per day) \\
$0 / 01$ & $0 / 19 \pm 0 / 04$ & $0 / 35 \pm 0 / 04$ & Nuts (per day) \\
\hline
\end{tabular}

Table 3 Comparison of clinical and biochemical parameters between the two groups

\begin{tabular}{llll}
\hline Proup & $\begin{array}{l}\text { Nutritional Factors } \\
\text { Patient(2I) }\end{array}$ & Control(24) & Nut \\
\hline $0 / 30$ & $6 / 3 \pm 2$ & $6 / 3 \pm 2$ & Age (years) \\
$0 / 2$ & $26 / 3 \pm 0 / 5$ & $25 / 4 \pm 0 / 7$ & $(\mathrm{~kg} / \mathrm{m} 2) \mathrm{BMI}$ \\
Jan-53 & $\% 95 / 5$ & $\% 95 / 5$ & Woman man $(\%)$ \\
$0 / 00 \mathrm{I}$ & $52 \%$ & $25 \%$ & Passive smokers \\
$0 / 3 \mathrm{I}$ & $\% 52 / 48$ & $\% 58 / 42$ & Urban life to rural \\
\hline
\end{tabular}

\section{Discussion}

This study predictive of lower level of zinc and copper in patient with perthes disease in contrast with control group that referred to emam hospital due to minor trauma. this difference, although, statistically was strong and significant but this study can nut be justified cause of lower level of zinc and copper in patient in contrast of control group.

Needed to be investigated further to be clarified if the lower level of zinc and copper in patient with perthes is due to low elementary diet in newborn and childhood and related to family socioeconomic. in this study consumption of fruits, nuts and fish was significantly lower in patient than control that given that these foods are the most important sources of copper and zinc so Could explain the blood levels lower copper and zinc in patients with Perthes. Also, patients with Perthes significantly more than the control group exposed to tobacco. In the study that Mr. Handeland and others in 2002 on the spot deer red mountain Norway did it was observed that copper deficiency osteochondrosis of have. ${ }^{12}$ also check and colleagues found that dietary supplements of copper in horses to protect the development of osteochondrosis have contribution Gee et al. ${ }^{13}$ no effect of copper supplements did not prevent the development of osteochondrosis. ${ }^{13,14}$ In this study lower level of zinc and copper in patient with perthes compared to control was demonstrated but zinc deficiency and copper to investigate the etiologic relationship with perthes disease requires further investigation. That the proof of this can be modified nutritional pattern of children with perthes disease be prevented.

\section{Acknowledgments}

None.

\section{Conflicts of interest}

None.

\section{References}

1. Herring JA Legg - Calve Perthes discase. I 1linois, American Academy of orthopaedic surgeons. 1996

2. Goff CW, shutkin NM, Hersey MR Legg Calve perthes syndrome and related osteo chondroses of youth. Chaarles C Thomas. Springfield IL USA. 1954

3. Hall AJ, Barker DJ, Dangerfield PH et al. Small feet and Perthes discase. Bone joint surg. 1988;70B:611-613.

4. Hall Aj, Margehes BM, Barker DJP, et al. Low blood Manganes leves in liver pool children with perthes disease. Paediatr perinat Epidemiol. 1989;3(2):131-136

5. Perry CA, Taylor JF Nunn A, Danger field PH Perthes disease and blood manganese levels. Arch Dis child. 2000;82(5):428.

6. Glueck CJ, Crawford A, Roy D et al. Association of antithrombatic factor deficiencies and hypofibrinolysis with legg-perthes disease. Bone joint surg. 1996;78(1):3-13.

7. Glueck CJ, Freiberg RA, Crawford A et al. Second hand smoke, hypofibrinolysis, and legg perthes disease. Clinorthop. 1998;352:152-167.

8. Wynne-Davies R, Gormley J Theetiology of perthes disease, Genetic epidemiological and growth factor in 310 Edinburgh and Glasgow patients. J Bone Joint surg. 1978;60(1):6-14.

9. Hall DJ (1986) Genetic aspect of perthes disease A critical review. Clin orthop. 1978;209:100-114.

10. Burch PR, Nevelas AB Perthes disease a new genctic hypothesis. Med Hypothesis. 1979;5(5):513-528.

11. Purry NA Perthes disease in three population groups in the Eastern cape region of South Africa. J Bone Joint surg 1982;64B:286-288.

12. Hadeland k, Bernhoft A Osteochondrosis associated with copper deficiency in legg-calve perthese disease. 1999

13. Pearce SG, Firth EC, grace ND et al. Effect of copper supplementation on the evidence of developmental orthopedic disease in pasturefed New Zealand thoroughboeds. Equine vet J. 1999;30(3):211-218.

14. Gee E, Davis M, Firth E, Jeffcott L et al. Osteochondrosis and copper Histalay of articulation cartilay frorm foals out of copper supplementd and non supplementd dams. Vet J 2007;173(1):111-119. 